\title{
Phase II Evaluation of Liposomal Doxorubicin with Docetaxel in Patients with Metastatic Breast Cancer
}

\author{
Julie Fasano $^{\mathrm{a}}$ Dawn Hershman ${ }^{\mathrm{b}} \quad$ Yelena Novik $^{\mathrm{a}}$ Benjamin Levinson ${ }^{\mathrm{a}} \quad$ Kim Blozie $^{\mathrm{b}}$ \\ Amy D. Tiersten ${ }^{\mathrm{a}}$ \\ a Department of Medicine, Division of Medical Oncology, New York University School of Medicine, \\ ${ }^{\mathrm{b}}$ The Herbert Irving Comprehensive Cancer Center, College of Physicians and Surgeons, Columbia University New York, USA
}

\section{Key Words}

Metastatic breast cancer · Doxil .

Liposomal encapsulation of doxorubicin - Docetaxel

\section{Summary}

Background: Taxanes are effective in treating metastatic breast cancer. Liposomal doxorubicin (LD) is as effective as doxorubicin but less toxic. Patients and Methods: This phase II trial assessed the combination of LD and docetaxel (D). Between 12/2002 and 9/2005, 12 women received monthly LD $\left(30 \mathrm{mg} / \mathrm{m}^{2}\right)$ and weekly $D\left(30 \mathrm{mg} / \mathrm{m}^{2}\right)$. Cycles were continued until progression or toxicity. Primary outcome was time to progression. Secondary endpoints included response rate, time to treatment failure, duration of response, survival, and toxicity. Results: Median age was 49 $(31-60)$ years. $9(75 \%)$ patients had estrogen receptor-positive or progesterone receptor-positive tumors. 5 (41.7\%) women had her-2/neu-positive tumors. 4 women stopped participation due to toxicity, and 7 due to progression. 8 (67\%) participants (95\% confidence interval (Cl) 51.6-94.5\%) had a partial response, and $2(16.7 \%)$ had stable disease. Median time to progression was 9.6 months $(95 \% \mathrm{Cl} 4.7-$ 12.2). Median time to treatment failure was 6.5 months $(95 \%$ Cl 4.4-10.5). Median survival was 22.1 months $(95 \% \mathrm{Cl} 9.6-$ 40.8). Median duration of partial response was 2.7 months (95\% Cl 2.4-10.5). 10 (83\%) women experienced grade $3 / 4$ toxicities: neutropenia $3(25 \%)$, infection $3(25 \%)$, stomatitis $5(41.7 \%)$, nausea $2(16.7 \%)$, vomiting $1(8.3 \%)$, dyspnea 2 (16.7\%), pericardial effusion 1 (8.3), and palmar-plantar erythrodysesthesia 1 (8.3\%). Conclusions: LD and D resulted in an encouraging response and unacceptable toxicities.

\section{Schlüsselwörter}

Metastasiertes Mammakarzinom · Doxil .

Liposomale Verkapselung von Doxorubicin - Docetaxel

\section{Zusammenfassung}

Hintergrund: Taxane sind wirksame Substanzen in der Behandlung des metastasierten Mammakarzinoms. Liposomales Doxorubicin (LD) ist genauso effektiv wie Doxorubicin, aber weniger toxisch. Patienten und Methoden: Die vorliegende Phase-II-Studie befasste sich mit der Kombination aus LD und Docetaxel (D). Zwischen Dezember 2002 und September 2005 wurden 12 Frauen mit monatlichem LD $\left(30 \mathrm{mg} / \mathrm{m}^{2}\right)$ und wöchentlichem $\mathrm{D}\left(30 \mathrm{mg} / \mathrm{m}^{2}\right)$ behandelt. Die Behandlungszyklen wurden bis zum Auftreten von Progression oder Toxizität fortgesetzt. Das primäre Outcome war die Zeit bis zur Progression. Sekundäre Endpunkte waren Ansprechrate, Zeit bis zum Therapieversagen, Dauer des Ansprechens, Überleben und Toxizität. Ergebnisse: Das mittlere Alter betrug 49 (31-60) Jahre. 9 (75\%) Patientinnen hatten östrogenrezeptorpositive oder progesteronrezeptorpositive Tumoren. 5 (41,7\%) Frauen hatten her-2/neu-positive Tumoren. 4 Frauen beendeten die Teilnahme an der Studie auf Grund von Toxizität und 7 auf Grund von Progression. 8 (67\%) Teilnehmerinnen (95\% Konfidenzinterval (KI) 51,6-94,5\%) zeigten ein partielles Ansprechen und 2 $(16,7 \%)$ eine stabile Erkrankung. Die mittlere Zeit bis zur Progression war 9,6 Monate (95\% KI 4,7-12,2). Die mittlere Zeit bis zum Therapieversagen betrug 6,5 Monate $195 \% \mathrm{KI}$ 4,4-10,5). Das mittlere Überleben war 22,1 Monate (95\% KI 9,6-40,8). Die mittlere Dauer des partiellen Ansprechens war 2,7 Monate (95\% KI 2,4-10,5). 10 (83\%) Frauen entwickelten Grad-3/4-Toxizitäten: Neutropenie $3(25 \%)$, Infektion 3 (25\%), Stomatitis 5 (41,7\%), Übelkeit 2 (16,7\%), Erbrechen $1(8,3 \%)$, Dyspnoe $2(16,7 \%)$, Perikarderguss $1(8,3)$ und Hand-Fuß-Syndrom 1 (8,3\%). Schlussfolgerungen: LD und D resultierten in vielversprechendem Ansprechen und inakzeptabler Toxizität.

\begin{tabular}{ll}
\hline KARGER & $\oplus$ 2010 S. Karger GmbH, Freiburg \\
Fax +497614520714 & Accessible online at: \\
Information@Karger.de & www.karger.com/brc \\
www.karger.com &
\end{tabular}




\section{Introduction}

Doxorubicin, an anthracycline antibiotic, is one of the most active agents used to treat metastatic breast cancer (MBC). However, the clinical utility of doxorubicin is limited by its cumulative dose-dependent propensity to cause cardiac damage. Pegylated liposomal doxorubicin (LD) is doxorubicin encapsulated in liposomes. Clinical trials have demonstrated that LD is just as effective as doxorubicin, and with less toxicity [1].

Docetaxel (D) has significant activity in both frontline and second-line therapy for advanced breast cancer [2-6]. Given the significant activity doxorubicin and D exhibit as single agents in the treatment of breast cancer, their non-overlapping side effect profiles, and their lack of clinical cross-resistance, much research has been done to assess the benefit of combining these agents to treat MBC. The doxorubicin/D doublet has been shown to be a highly active first-line treatment regimen in $\mathrm{MBC}$ [7-13].

Several studies have been performed to assess whether the $\mathrm{LD} / \mathrm{D}$ doublet can achieve the same therapeutic response, but most have not evaluated a weekly schedule of $\mathrm{D}$. When $\mathrm{D}$ is dosed weekly, myelosuppression is diminished but fatigue becomes the major toxicity [14-17]. A phase I trial was conducted to determine the maximum tolerated dose of D that could be administered with LD, with and without granulocyte colony-stimulating factor (G-CSF) support in 37 patients with metastatic cancer. If $\mathrm{LD} / \mathrm{D}$ were given without G-CSF support, the recommended dosing was $30 / 60 \mathrm{mg} / \mathrm{m}^{2}$ every 3 weeks. If the combination was given with G-CSF support, $30 \mathrm{mg} / \mathrm{m}^{2}$ of LD and $80 \mathrm{mg} / \mathrm{m}^{2}$ of D could be administered every 3 weeks [18]. In a phase II study, 44 women with MBC received LD $30 \mathrm{mg} / \mathrm{m}^{2}$ and D $75 \mathrm{mg} / \mathrm{m}^{2}$ every 3 weeks for 6 cycles. The overall response rate (ORR) was $64.3 \%$, with $6(14.3 \%)$ patients attaining a complete response (CR) and $21(50 \%)$ patients attaining a partial response (PR). Median progression-free survival and overall survival (OS) were not reached. Grade 3 and 4 toxicities included neutropenia (18.4\%), palmar-plantar erythrodysesthesia (PPE) (2.3\%), and neurotoxicity $(2.3 \%)$ [19].

Given the therapeutic efficacy of single agents in the treatment of MBC, many practitioners use single-agent therapy rather than combination therapy to avoid toxicity. However, when patients with $\mathrm{MBC}$ have a good performance status, extensive visceral involvement, or rapid tumor growth, they may benefit from combination therapy. Combination therapy may achieve higher response rates and longer median time to progression (TTP) and OS [20]. The antitumor efficacy of combination LD and D and the reduced cardiotoxicity in its side effect profile make this doublet a viable treatment option for women with MBC. The objective of this phase II study was to determine both the efficacy and toxicity of weekly D in combination with monthly LD as first-line therapy in patients with MBC.

\section{Patients and Methods}

\section{Patient Population}

Women aged 18-75 years with histologically confirmed MBC with measurable or evaluable disease were eligible for enrollment. Patients were recruited from NYU Medical Center and Columbia University Medical Center. Participants could have received previous hormonal or adjuvant chemotherapy. Patients who had received prior chemotherapy for metastatic disease were ineligible. Prior anthracycline exposure was permitted if the total doxorubicin dose was less than or equal to $300 \mathrm{mg} / \mathrm{m}^{2}$ intravenous (IV) bolus or $400 \mathrm{mg} / \mathrm{m}^{2}$ IV continuous infusion. The last dose of anthracycline must have been at least 12 months prior to study enrollment. Patients could have central nervous system (CNS) metastases only if they had completed cranial irradiation at least 3 months before study entry, were asymptomatic, and not taking corticosteroids for this condition. Inclusion criteria included: a Karnofsky performance status greater than or equal to $60 \%$; no history of cardiac disease or clinical evidence of congestive heart failure (CHF), a left ventricle ejection fraction (LVEF) greater or equal to $50 \%$; platelets greater than or equal to 100,000 ; a hemoglobin greater than or equal to $9 \mathrm{~g} / \mathrm{dl}$; an absolute neutrophil count greater than or equal to 1,500 cells $/ \mathrm{mm}^{3}$; a creatinine less than or equal to $2.5 \mathrm{mg} / \mathrm{dl}$; an aspartate aminotransferase, alanine transaminase, and alkaline phosphatase less than or equal to twice the upper limit of normal except if attributed to tumor; and a bilirubin within normal limits. Exclusion criteria included: any serious medical or psychiatric illness that might prevent informed consent or intensive treatment (e.g. serious infection), and a history of prior malignancies more than 5 years prior to study enrollment with the exception of curatively-treated basal cell or squamous carcinoma of the skin or carcinoma in situ of the cervix. Patients were expected to have a life expectancy of greater than 3 months. Patients gave written informed consent in accordance with the Declaration of Helsinki.

\section{Treatment Schedule and Dose Adjustments}

Patients received both D $\left(30 \mathrm{mg} / \mathrm{m}^{2}\right)$ IV and $\mathrm{LD}\left(30 \mathrm{mg} / \mathrm{m}^{2}\right) \mathrm{IV}$ on day 1 , week 1. Participants received D $\left(30 \mathrm{mg} / \mathrm{m}^{2}\right)$ IV on day 8 , week 2 , and day 15 , week 3. Chemotherapy was held on day 22, week 4. Patients were to receive antiemetics and other supportive treatment, i.e. colony-stimulating factors, at the discretion of the treating physician. Cycles were repeated every 28 days until one of the following took place: patients had received a cumulative anthracycline dose of $550 \mathrm{mg} / \mathrm{m}^{2}$; patients had disease progression on therapy; unacceptable toxicities (as determined by the physician) developed; clinical or laboratory adverse events occurred; LVEF fell to less than $45 \%$ or fell $20 \%$ from baseline; or participants did not comply with protocol requirements.

The National Cancer Institute (NCI) Common Toxicity Criteria were utilized for toxicity grading. If a patient developed prolonged grade 4 neutropenia or thrombocytopenia, treatment was withheld until both resolved to grade 1 . Treatment could be resumed with a $25 \%$ reduction in doses for both drugs. If neutropenia persisted without significant thrombocytopenia, colony-stimulating factor could be given with the next course of therapy, without any dose modification. For patients exhibiting grade 3 or 4 PPE or stomatitis, treatment was held for 2 weeks or until the toxicity resolved to grade $0-1$. The dose of $L D$ was reduced by $25 \%$. If there was no resolution after 2 weeks, LD was discontinued. If the total bilirubin rose to greater than 1.2 but less than or equal to $3.0 \mathrm{mg} / \mathrm{dl}$, then the dose of LD was reduced by $25 \%$. If the bilirubin increased to greater than $3 \mathrm{mg} / \mathrm{dl}$ and was unrelated to treatment with $\mathrm{LD}$, the dose was reduced by $50 \%$. If the elevation of bilirubin to greater than $3 \mathrm{mg} / \mathrm{dl}$ was thought to be secondary to LD, the patient was withdrawn from the study. For all other grade 3 or 4 non-hematologic events, a $25 \%$ reduction of the LD and D dose was recommended until the toxicity resolved to less than or equal to grade 2 .

Baseline LVEF was performed on all patients prior to enrollment. After the patient received a cumulative anthracycline dose of greater than $350 \mathrm{mg} / \mathrm{m}^{2}$, a MUGA or 2-d echo was obtained every 3 cycles. If during treatment the LVEF fell to less than $45 \%$ or fell $20 \%$ from the baseline level, LD was discontinued. 


\section{Treatment Evaluation}

Initial evaluation included a thorough history, physical examination, hematology, and serum biochemistry tests, tumor markers (CEA, and CA27.29), computed tomography scans of the chest, abdomen, and pelvis, and bone scan. Radiologic assessment of response was performed every 2 cycles.

\section{Statistical Analysis}

This was a non-comparative phase II trial designed to examine the efficacy and toxicity of combination D and LD when utilized as first-line therapy in patients with MBC. TTP was the primary endpoint and was calculated from date on study to date of progression or death (any cause), whichever occurred first. A patient who was alive and progression-free at the end of study was censored. The planned sample size of 40 would provide $80 \%$ power to detect an increase of $60 \%$ in TTP from 5 to 8 months. The Kaplan-Meier method was used to plot the TTP curve and estimate the median TTP with a 95\% confidence interval (CI). Secondary endpoints included: time to treatment failure (TTF), OS, ORR, duration of response, and toxicity. TTF was calculated from the date on study to date of disease progression, death (any cause), or toxicity, whichever occurred first. A patient who was alive and progression-free with no toxicity at the end of study was censored. The Kaplan-Meier method was used to estimate the median TTF with a 95\% CI. OS was calculated from the date on study to date of death (any cause). A patient who was alive at the end of study was censored. The Kaplan-Meier method was used to estimate the median OS time with a $95 \%$ CI. ORR was defined as the proportion of patients with a CR or PR. A $95 \%$ CI was calculated for the response rate. The duration of response for any patient with either CR or PR was calculated from the first documentation of response to the date of disease progression or death (any cause), whichever occurred first. A patient who was alive and progression-free at the end of study was censored. The Kaplan-Meier method was used to plot the response duration curve and estimate the median response duration with a $95 \%$ CI. All calculations used SAS 9.1.3 (SAS Institute Inc., Cary, NC, USA).

\section{Results}

\section{Patient Characteristics}

Between December 2002 and September 2005, 12 women received treatment. The median age was 49 (range 31-60) years. Ten women had an ECOG performance status of 1, and 2 women had an ECOG performance status of 2 . Nine (75\%) participants had tumors that were estrogen receptor-positive $(\mathrm{ER}+)$ or progesterone receptor-positive $(\mathrm{PR}+)$. Five $(41.7 \%)$ women had malignancies that overexpressed her-2/neu. Information about tumor grade was available for 9 participants. Three women had grade III invasive ductal cancer, and 6 women had grade II invasive ductal cancer. At the time of enrollment, bone, lung, liver, skin, and lymph node metastases were reported in $58.3,58.3,41.7,25$, and $16.7 \%$ of the patients, respectively. Seven women had received prior adjuvant chemotherapy. Four participants had received anthracyclinebased therapy. Seven women had received prior hormonal therapy. All women with hormone-positive disease had received hormonal therapy in the adjuvant setting. Six patients with metastatic hormonal responsive disease had received a median number of 2 lines of antihormonal therapy prior to inclusion into the trial, with a range of 1 to 2 lines of therapy (table 1).
Table 1. Patient

characteristics

\begin{tabular}{ll}
\hline Median age, years (range) & $49(31-60)$ \\
\cline { 2 - 2 } & Patients, n (\%) \\
\cline { 2 - 2 } Patients entered & 12 \\
ECOG performance status & \\
1 & $10(83.3)$ \\
2 & $2(16.7)$ \\
ER+/PR+/both & $9(75)$ \\
Her-2/neu-positive & $5(41.7)$ \\
Tumor grade & \\
II & $6(50)$ \\
III & $3(25)$ \\
Site of metastasis & $7(58.3)$ \\
Bone & $7(58.3)$ \\
Lung & $5(41.7)$ \\
Liver & $3(25)$ \\
Skin & $2(16.7)$ \\
Lymph nodes & \\
Prior treatments & $7(58.3)$ \\
Adjuvant chemotherapy & $4(33.3)$ \\
Anthracycline-based & $7(58.3)$ \\
Hormonal therapy & \\
\hline anformation available for 9 participants. \\
ER = Estrogen receptor; PR = progesterone \\
receptor. \\
\hline
\end{tabular}

\section{Treatment Administration}

A total of 64.5 cycles of chemotherapy were administered, with a median number of 4 (range 1-12) cycles per patient. Toxicity caused a delay in treatment for 7 patients. Side effects led to dose reduction of LD by $25 \%$ in 5 patients. Toxicity led to dose reduction of $\mathrm{D}$ by $25 \%$ in 1 patient. Toxicity led to the removal of 4 participants from the protocol.

\section{Efficacy}

The median follow-up time for the 12 women was 14.7 (range 0.9-40.8) months. Eleven of 12 women were taken off study because of disease progression or toxicity. One woman was taken off study for administrative reasons. Out of the 11 women, 7 have died, 3 remain alive with disease, and 1 was lost to follow-up. The woman lost to follow-up was censored at date off treatment due to toxicity. The estimated median TTP was 9.6 months (95\% CI 4.7-12.2) (fig. 1, table 2). The estimated median TTF was 6.5 months (95\% CI 4.4-10.5) (fig. 2, table 2). The estimated median OS was 22.1 months (95\% CI 9.6-40.8) (fig. 3, table 2). Eight (67\%) participants (95\% CI 51.6-94.5\%) had a PR to chemotherapy, and $2(16.7 \%)$ had stable disease. For the 8 women who had a PR to chemotherapy, the estimated median duration of response was 2.7 months (95\% CI 2.4-10.5) (fig. 4). All patients with her-2/neu-positive metastatic disease went on to receive trastuzumab-based chemotherapy regimens.

\section{Toxicity}

Seven of 12 women were taken off study because of disease progression. One woman developed a grade 3 infection and 
Table 2. Estimated medians and confidence intervals ( $95 \%$ CI) for outcomes $(\mathrm{n}=12)$

\begin{tabular}{lcc}
\hline & $\begin{array}{l}\text { Estimated } \\
\text { median, months }\end{array}$ & $95 \%$ CI \\
\hline TTP & 9.6 & $4.7-12.2$ \\
TTF & 6.5 & $4.4-10.5$ \\
OS & 22.1 & $9.6-40.8$ \\
\hline
\end{tabular}

$\mathrm{TTP}=$ Time to progression; TTF $=$ time to treatment failure; $\mathrm{OS}=$ overall survival.
Table 3. Patient toxicity

\begin{tabular}{lllll}
\hline & \multicolumn{5}{l}{ Toxicity, $\mathrm{n}(\%)$} \\
\cline { 2 - 5 } & Grade 1 & Grade 2 & Grade 3 & Grade 4 \\
\hline Neutropenia & $4(33.3)$ & 0 & $3(25)$ & 0 \\
Anemia & $9(75)$ & 0 & 0 & 0 \\
Thrombocytopenia & $4(33.3)$ & 0 & 0 & 0 \\
Infection & $1(8.3)$ & 0 & $3(25)$ & 0 \\
Nausea & $4(33.3)$ & $3(25)$ & $2(16.7)$ & 0 \\
Emesis & $3(25)$ & $2(16.7)$ & $1(8.3)$ & 0 \\
Stomatitis & 0 & $3(25)$ & $5(41.7)$ & 0 \\
Dyspnea & 0 & 0 & $1(8.3)$ & $1(8.3)$ \\
Palmar-plantar erythrodysia & $1(8.3)$ & 0 & $1(8.3)$ & 0 \\
Pericardial effusion & 0 & 0 & $1(8.3)$ & 0 \\
Constipation & $1(8.3)$ & $7(58.3)$ & 0 & 0 \\
Diarrhea & 0 & $1(8.3)$ & 0 & 0 \\
Fatigue & $5(41.7)$ & $6(50)$ & 0 & 0 \\
Edema & $1(8.3)$ & $1(8.3)$ & 0 & 0 \\
Elevated liver function tests & 0 & $1(8.3)$ & 0 & 0 \\
Neuropathy & $5(41.7)$ & $1(8.3)$ & 0 & 0 \\
Myalgias & $4(33.3)$ & $3(25)$ & 0 & 0 \\
Hyperlacrimentation & $1(8.3)$ & $1(8.3)$ & 0 & 0 \\
Hot flashes & $1(8.3)$ & $1(8.3)$ & 0 & 0 \\
Nail changes & $2(16.7)$ & $1(8.3)$ & 0 & 0 \\
Anorexia & $2(16.7)$ & $2(16.7)$ & 0 & 0 \\
Alopecia & $1(8.3)$ & $1(8.3)$ & 0 & 0 \\
Mucositis & $1(8.3)$ & $2(16.7)$ & 0 & 0 \\
\hline & & & & \\
\hline
\end{tabular}

grade 4 dyspnea after 1 cycle of chemotherapy. She was found to have gram-positive cocci septicemia and died. Three patients asked to be removed from the study because of side effects. Three women experienced grade 3 neutropenia. None of the participants developed neutropenic fever. Three women experienced a grade 3 infection. Non-hematologic grade 3 and 4 toxicities included grade 3 nausea $(16.7 \%)$, grade 3 emesis (8.3\%), grade 3 stomatitis (41.7), grade 3 and 4 dyspnea $(16.7 \%)$, grade 3 PPE $(8.3 \%)$, and grade 3 pericardial effusion $(8.3 \%)$. No women developed signs and symptoms of CHF while on study (table 3).

\section{Discussion}

Side effects associated with the combination of D and doxorubicin include febrile neutropenia, nausea, and stomatitis. These toxicities are amenable to therapeutic intervention.
However, a commonly recognized adverse event that occurs in conjunction with anthracycline use is a reduction in LVEF and the development of CHF $[9,12,13]$.

In a phase II trial conducted by Alexopoulos et al. [19], 44 patients received $\mathrm{LD} 30 \mathrm{mg} / \mathrm{m}^{2}$ (day 1) and D $75 \mathrm{mg} / \mathrm{m}^{2}$ (day 2) every 3 weeks. A small percentage (18.4) of patients developed grade 3-4 neutropenia. Neutropenia led to the removal of 1 patient from their cohort. These results are similar to results reported in our clinical trial. In the present study, 3 women experienced grade 3 non-febrile neutropenia, and neutropenia lead to the reduction of the LD dose for 1 patient and the delay of chemotherapy for 2 patients. The frequency of grade 3 and 4 adverse events was higher in our phase II trial when compared to the trial conducted by Alexopoulos et al. [19]. The total dose of $\mathrm{D}$ given over 3 weeks in our trial was $90 \mathrm{mg} / \mathrm{m}^{2}$, while the total dose of D given every 3 weeks in the Alexopoulos et al. [19] study was $75 \mathrm{mg} / \mathrm{m}^{2}$. In fact, most phase II and phase III trials that have incorporated D into an anthracycline-based treatment regimen have done so at doses raging from 60 to $75 \mathrm{mg} / \mathrm{m}^{2}$. The higher doses of $\mathrm{D}$ given to our study cohort may have led to the development of more grade 3 and 4 adverse events. Surprisingly, the incidence of PPE in our trial and the Alexopoulos et al. [19] study was quite low. This result could be attributed to the smaller dose of LD $30 \mathrm{mg} / \mathrm{m}^{2}$ utilized in both studies. As expected, no patient in the present study developed a reduction in her LVEF. The diminution of cardiac risk conferred by the use of LD has been substantiated in several other clinical trials [1, 19, 21].

\section{Conclusions}

Since this protocol was established, the use of taxanes in the adjuvant setting and the use of biologic agents in combination with chemotherapeutic agents in the adjuvant and metastatic settings have become standard of care. This may explain why there was a small number of patients recruited to participate in this trial. The combination of LD and D was highly active as a first-line treatment regimen in patients with MBC. The rate of grade 3 and 4 toxicity was unacceptably high. The combination may warrant further evaluation with prophylactic growth factors or altered dose schedules.

\section{Supplemental Figures}

Fig. 1. Kaplan-Meier progression-free survival curve.

Fig. 2. Kaplan-Meier failure-free survival curve.

Fig. 3. Kaplan-Meier overall survival curve.

Fig. 4. Kaplan-Meier response duration curve.

To access the figures please refer to www.karger.com/ DOI/10.1159/000272119. 


\section{Conflict of Interest Statement}

Dr. Amy Tiersten is on the speakers' bureau for Sanofi Aventis and has received honoraria from Aventis. The other authors have no conflicts of interest to disclose. Orthobiotech supplied research funding.

\section{References}

1 O'Brien MER, Wigler N, Inbar M, et al.: Reduced cardiotoxicity and comparable efficacy in a phase III trial of pegylated liposomal doxorubicin $\mathrm{HCl}$ (CAELYX/Doxil) versus conventional doxorubicin for first-line treatment of metastatic breast cancer. Ann Oncol 2004;15:440-449.

$\checkmark 2$ Chevallier B, Fumoleau P, Kerbat P, et al.: Docetaxel is a major cytotoxic drug for the treatment of advanced breast cancer: a phase II study of the Clinical Screening Cooperative Group of the European Organization for Research and Treatment of Cancer. J Clin Oncol 1995;13:314.

$\checkmark 3$ Hudis CA, Seidman AD, Crown JA, et al.: Phase II and pharmacologic study of docetaxel as initial chemotherapy for metastatic breast cancer. J Clin Oncol 1996;14:58.

4 Trudeau ME, Eisenhauer EA, Higgins BP, et al.: Docetaxel in patients with metastatic breast cancer: a phase II study of the National Cancer Institute of Canada Clinical Trials Group. J Clin Oncol 1996; 14:422.

5 Ravdin PM, Burris HA, Cook G, et al.: Phase II trial of docetaxel in advanced anthracycline-resistant or anthracendione-resistant breast cancer. J Clin Oncol 1995;13:2879.

6 Valero V, Holmes FA, Walters RS, et al.: Phase II trial of docetaxel. A new, highly effective antineoplastic agent in the management of patients with metastic breast cancer. J Clin Oncol 1995;13:2886.

7 Paridaens R, Van Aelst F, Georgoulias V, et al.: A randomized phase II study of alternating and sequential regimens of docetaxel and doxorubicin as first-line chemotherapy for metastatic breast cancer. Ann Oncol 2003;14:433-440.

${ }_{8}$ Alba E, Ribelles N, Anton A, et al.: Sequential doxorubicin and docetaxel as first-line treatment in metastatic breast cancer: a GEICAM-9801 phase II study. Breast Cancer Res Treat 2003;77:1-8.
9 Cresta S, Grasselli G, Mansutti M, et al.: A randomized phase II study of combination, alternating, and sequential regimens of doxorubicin and docetaxel as first-line chemotherapy for women with metastatic breast cancer. Ann Oncol 2004;15:433439.

10 Sparano, J, O'Neil A, Schaefer PL, et al.: Phase II trial of doxorubicin and docetaxel plus granulocyte colony-stimulating factor in metastatic breast cancer: Eastern Cooperative Oncology Group Study E1196. J Clin Oncol 2000;18:2369-2377.

11 Smith RE, Anderson SJ, Lembersky BC, et al.: Phase II trial of a doxorubicin/ docetaxel doublet for locally advanced and metastatic breast cancer: results from National Surgical Adjuvant Breast and Bowel Project Trial BP-57. Clin Breast Cancer 2004;5:208-215.

12 Nabholtz, JM, Falkson C, Campos D, et al.: Docetaxel and doxorubicin compared with doxorubicin and cyclophosphamide as first-line chemotherapy for metastatic breast cancer: results of a randomized, multicenter, phase III trial. J Clin Oncol 2003;21:968-975.

13 Bontenbal M, Creemers GJ, Braun HJ, et al.: Phase II to phase III study comparing doxorubicin and docetaxel with fluorouracil, doxorubicin, and cyclophosphamide as first-line chemotherapy in patients with metastatic breast cancer: results of a Dutch community setting trial for the Clinical Trial Group of the Comprehensive Cancer Centre. J Clin Oncol 2005;23:7081-7088.

14 Tomiak E, Piccart MJ, Kerger J, et al.: Phase I trial of docetaxel administered as a 1-hour intravenous infusion on a weekly basis. J Clin Oncol 1994;12: 1458.
15 Hainsworth JD, Burris HA, Erland JB, et al. Phase I trial of docetxel administered by weekly infusion in patients with advanced refractory cancer. J Clin Oncol 1998;16:2164.

16 Loffler TM, Freund W, Droge C, et al.: Activity of weekly taxotere (TXT) in patients with metastatic breast cancer. Proc Am Soc Clin Oncol 1998;17:113a(abstr 435).

17 Briasoulis E, Karavasilis, Anastasopoulos D, et al.: Phase I trial of weekly administration of docetaxe in minimally pretreated cancer patients: a feasibility and cumulative toxicity study. Ann Oncol 1998; 9:101(abstr 385, suppl 2).

18 Pavlick AC, Chodkiewicz C, Liebes L, et al.: A phase I and pharmacokinetic study of docetaxel combined with Doxil (pegylated liposomal doxorubicin) without and with granulocyte colony stimulating factor. Anticancer Drugs 2004;15:119-125.

19 Alexopoulos A, Karamouzis MV, Stavrinides H, et al.: Phase II study of pegylated liposomal doxorubicin (Caelyx) and docetaxel as first-line treatment for metastatic breast cancer. Ann Oncol 2004;15: 891-895.

20 Albain K: Phase three registration trial of gemcitabine/paclitaxel vs. paclitaxel in patients with anthracycline-pretreated metastatic breast cancer. Proc Am Soc Clin Oncol 2004;23(abstr 510).

21 Batist G, Ramakrishnan G, Rao CS, et al.: Reduced cardiotoxicity and preserved antitumor efficacy of liposome-encapsulated doxorubicin and cyclophosphamide compared with conventional doxorubicin and cyclophosphamide in a randomized, multicenter trial of metastatic breast cancer. J Clin Oncol 2001;19:1444-1454. 